\title{
Sustaining Patient Portal Continuous Use Intention and Enhancing Deep Structure Usage: Cognitive Dissonance Effects of Health Professional Encouragement and Security Concerns
}

\author{
Murad Moqbel $^{1}$ (D) - Barbara Hewitt ${ }^{2}$ - Fiona Fui-Hoon Nah ${ }^{3} \cdot$ Rosann M. McLean ${ }^{4}$ \\ Accepted: 15 June 2021 / Published online: 21 June 2021 \\ (C) The Author(s), under exclusive licence to Springer Science+Business Media, LLC, part of Springer Nature 2021
}

\begin{abstract}
Sustaining patient portal use is a major problem for many healthcare organizations and providers. If this problem can be successfully addressed, it could have a positive impact on various stakeholders. Through the lens of cognitive dissonance theory, this study investigates the role of health professional encouragement as well as patients' security concerns in influencing continuous use intention and deep structure usage among users of a patient portal. The analysis of data collected from 177 patients at a major medical center in the Midwestern region of the United States shows that health professional encouragement helps increase the continuous use intention and deep structure usage of the patient portal, while security concerns impede them. Interestingly, health professional encouragement not only has a direct positive influence on continuous use intention and deep structure usage but also lowers the negative impact of security concerns on them. The research model explains a substantial variance in continuous use intention (i.e., 40\%) and deep structure usage (i.e., 32\%). The paper provides theoretical implications as well as practical implications to healthcare managers and providers to improve patient portal deep structure usage and sustained use for user retention.
\end{abstract}

Keywords Patient portal · Health professional encouragement $\cdot$ Security concerns $\cdot$ Continuous use $\cdot$ Deep structure usage $\cdot$ Consumer health IT

Murad Moqbel

murad.moqbel@utrgv.edu

Barbara Hewitt

bh05@txstate.edu

Fiona Fui-Hoon Nah

nahf@mst.edu

Rosann M. McLean

rblackmore@kumc.edu

1 Information Systems Department, University of Texas Rio Grande Valley, Edinburg, TX, USA

2 Health Information Management Department, Texas State University, San Marcos, TX, USA

3 Department of Business and Information Technology, Missouri University of Science and Technology, Rolla, MO, USA

4 Department of Health Information Management, University of Kansas Medical Center, Kansas City, KS, USA

\section{Introduction}

Patient portals are defined as provider-tethered web-based applications that enable patients to access health information typically managed by a healthcare provider (Moqbel et al., 2020; Otte-Trojel et al., 2015). Evidence suggests that access to patient portals has tremendous benefits to healthcare providers (Fraccaro et al., 2018; O'Connor \& O'Reilly, 2018; Schickedanz et al., 2013). It helps reduce costs by reducing the number of unnecessary patient visits that can be mitigated by the patient portal's secure messaging feature (Raghu et al., 2015). The benefits that patients receive from patient portal use include secure communications with health providers, convenience in scheduling appointments, ease of requesting prescription refills, online access and servicing of patient accounts, enhancement in patient self-management of chronic illnesses, and availability of educational resources to patients (Kruse et al., 2015a; Schickedanz et al., 2013; Serrano et al., 2020). Patients indicated that the benefits of using secure messaging include satisfaction, efficiency, improved visits, and access to data outside office visits (Wade-Vuturo et al., 2013; Wang et al., 2021). 
Despite the Health Information Technology for Economic and Clinical Health (HITECH) Act that was passed more than a decade ago in which healthcare professionals are incentivized to adopt meaningful use of digital health (Rathert et al., 2019), $80 \%$ of patients are still reluctant to use patient portals (Heath, 2018a; Heath, 2018b). Barriers to enrolling in a patient portal include lack of information such as not knowing that the portal exists, failure to access the portal, negative attitudes toward the patient portal, preference for nonelectronic communications, and technology-related issues such as lack of Internet access or computer proficiency (Goel et al., 2011a; Goel et al., 2011b). Security concerns have been major issues in the adoption of patient portals (Mukherjee \& Nath, 2003; Sathye, 1999; Son et al., 2021). In comparison to similarly security-sensitive industries such as banking, in which almost $75 \%$ of Americans access their bank accounts online (Federal Reserve, 2016), merely 30\% of American patients used patient portals in 2018 (Heath, 2018b). Evidence shows that patient portal use tapered off after first use and dropped from $77 \%$ in the first month to $30 \%$ in half a year (Weingart et al., 2006); however, the reasons that individuals were dropping from enrollment were unclear. In another study, Goel et al. (2011a) determined that $25 \%$ of 159 patients who participated in their survey indicated that security was a major concern when considering activating an account and using a patient portal. Anthony et al. (2018) determined that $22 \%$ of the people surveyed were not using patient portals due to security and privacy concerns. Hence, the exigency to find factors that impact patient portal continuous use is highly warranted because the full benefits of implementing digital health technologies (Thambusamy \& Palvia, 2020) by healthcare organizations cannot be realized if continuous use by patients cannot be sustained.

Past research examined several factors that influence the adoption of patient portals, including personal factors (e.g., income, gender, and race), human-technology-factors (e.g., perceived ease of use and usefulness), and organizational factors (Abd-alrazaq et al., 2019; Ancker et al., 2011; Fowles et al., 2004; Goel et al., 2011a; Goel et al., 2011b; Hsu et al., 2005; Huvila et al., 2018; Li et al., 2014; Nicholas et al., 2003; Roblin et al., 2009; Sarkar et al., 2010; Sarkar et al., 2011; Weingart et al., 2006). However, despite the considerable merits of these studies in enhancing our understanding of the role of these factors in patient portal user behaviors, the existing literature largely overlooks the importance of continuous use and deep structure usage of patient portals among users (those who reported having an account) and the role of cognitive dissonance in sustaining continuous use and deep structure usage, such as weighing health professional encouragement against security concerns. Deep structure usage of a patient portal refers to the use of features supporting healthcare management.
In the context of patient portal use, health professional encouragement refers to giving support, recommendations, and confidence to patients in their use of patient portals. Health professional encouragement, a type of social influence that is also known as a normative belief or subjective norm, is rarely studied in the patient portal use context. Yet, social influence is widely studied in other contexts, including social media, enterprise resource planning, and wearable fitness (Ajzen, 1991; Hsu et al., 2013; Ifinedo, 2012; Lunney et al., 2016; Nah \& Tan, 2015; Seethamraju et al., 2018). Scholars who examined technology adoption in various contexts found social influence impacted technology adoption. In this paper, we study a unique aspect of social influence by considering the role of health professional encouragement in the posttechnology-adoption context (i.e., patient portal continuous use).

Due to an increasing trend in the number of security breaches, security has become a main concern for healthcare institutions and patients (Bodenheimer \& Grumbach, 2003; Cantor, 2001; Collins et al., 2017). Security concerns in the healthcare context refer to concerns about the risks and vulnerabilities associated with patient health information and the protective actions taken against these threats. Individuals often rely on security perceptions in the decision-making process to adopt a certain behavior or technology (Angst \& Agarwal, 2009; Archer \& Cocosila, 2014; Dai \& Chen, 2015; Featherman et al., 2010; Hsu et al., 2013; Zailani et al., 2015). As such, we contend that security concerns can play an important role in patient portal use.

Drawing on cognitive dissonance theory (CDT), we investigate the cognitive dissonance effects of health professional encouragement and security concerns on the continuous use intention and deep structure usage of a patient portal among its existing users. This study makes several key contributions to the field. First, the literature has, to some extent, ignored the examination of issues in sustaining continuous use of patient portals, especially given the high churn rates in patient portal use, thus creating a gap in an important stage of technology use (post-adoption) that is addressed in this study. Second, the literature has largely overlooked the role of cognitive dissonance in the post-adoption (continuous use) of health IT. Drawing on CDT, we identified an enabling factor (i.e., health professional encouragement) and a hindering factor (i.e., security concerns) to understand users' trade-off in resolving cognitive dissonance in the decisions on continuous use of a patient portal. Third, we argue that due to cognitive dissonance, health professional encouragement might help mitigate the negative effects of security concerns on the continuous use and deep structure usage of patient portals. Hence, we examine the moderating role of health professional encouragement on the relationships between security concerns and continuous use intentions as well as deep structure usage of patient portals. Understanding the interaction effect of health 
professional encouragement and security concerns is important to provide health institutions with guidelines for boosting patient portal continuous use and the extent of structural usage.

The rest of the paper is organized as follows: Section 2 provides the literature review. Section 3 presents the theoretical foundation and hypotheses. Section 4 describes the research method, and section 5 presents the results. Section 6 discusses the findings, and section 7 concludes the paper.

\section{Literature Review and Research Background}

\subsection{Patient Portals}

Interest in the adoption and use of patient portals is widespread since patients' actual usage is quite low. For example, only roughly $16 \%(11,000)$ of close to 75,000 active adult patients of a major federally qualified healthcare network requested access codes for the patient portal, and a little less than 10\% (7100) activated their accounts (Ancker et al., 2011). Byczkowski et al. (2014) found that 28\% of 1900 families obtained an account for the patient portal; however, only half of them (i.e., those with an account) used the portal once, and only $7.5 \%$ continued to use the portal. In 2017 , out of $52 \%$ of individuals nationwide that were offered online access to their medical record by a health care provider or insurer, only about half $(54 \%)$ of them accessed their account within a year (Patel \& Johnson, 2018).

Researchers have used different theories to examine the adoption of patient portals, such as theory of planned behavior (Emani et al., 2016), technology acceptance model (Kim \& Park, 2012; Razmak \& Bélanger, 2018), unified theory of acceptance and use of technology (Tavares \& Oliveira, 2016), and diffusion of innovation (Emani et al., 2018; Wang et al., 2021). The findings from these studies have returned mixed results. While some studies have explored CDT in the context of pre-adoption of technology (Alhudaithy \& Kitchen, 2009; Marikyan et al., 2020; Venkatesh \& Goyal, 2010), we did not find any research that has explored CDT in examining the postadoption - continuous use and deep structure usage - of patient portals. This research will use CDT as a lens to examine opposing factors influencing the continuous use and structural extent of usage of a patient portal. We purport that users will perceive dissonance about using these systems due to security concerns in accessing their records through patient portals. However, if their physicians and other health professionals recommend using these systems, it could help them overcome the dissonance concerns.

\subsection{Security Concerns}

Security has become an increasing concern in technology adoption, particularly in the context of healthcare and finance. For example, Dai and Chen (2015) found that security concerns have a negative impact on attitudes toward mobile commerce. Featherman et al. (2010) found that security concerns negatively impacted individuals' intent to use e-services such as banking. A study by Zailani et al. (2015) indicated that security concerns decreased healthcare professionals' willingness to adopt RFIDs.

Since the implementation of the Health Insurance Portability and Accountability Act (HIPAA), protected health information breaches have increased (Terry, 2014). Individuals are often made aware of those breaches through media outlets. Subsequently, health information security is becoming a major concern for both healthcare professionals and patients (Bodenheimer \& Grumbach, 2003; Cantor, 2001; Collins et al., 2017; Son, 2020). Concerns for security were mentioned in almost half (11 of 27) of the articles examining user adoption of patient portals to manage chronic diseases (Kruse et al., 2015a). Sakaguchi-Tang et al. (2017) also found that security was an issue for many who were asked to use a patient portal. More recently, patients expressed concerns over sharing information via a patient portal (Bajracharya et al., 2019; Collins et al., 2017).

Individuals expressed security concerns when they were considering using patient portals (Angst \& Agarwal, 2009; Archer \& Cocosila, 2014). Hsu et al. (2013) found that perceived security influenced individuals' intent to use a health information system even though the security threats were perceived to be low. Several systematic reviews indicated that security was a major concern when adopting patient portals (Irizarry et al., 2015; Kruse et al., 2015a; Li et al., 2014; OtteTrojel et al., 2016; Wakefield et al., 2012). Liu and Zhang (2014) also indicated that security has a negative impact on intent to create a personal health record regardless of the access method and whether the system is networked or standalone.

\subsection{Social Influence}

Researchers often explore the use of social influence, also referred to as a normative belief or subjective norm, when identifying factors that influence an individual's behavior, including adopting or using new technology (Ajzen, 1991; Emani et al., 2016; Ifinedo, 2012; Lunney et al., 2016). Family, friends, colleagues, educators, and others of authority can exert influence on one's behavior. Many studies have found a positive relationship between social influence and technology adoption (e.g., Ifinedo, 2012; Lunney et al., 2016; Moqbel, 2012; Nah \& Tan, 2015; Seethamraju et al., 2018). 
While many are influenced by referent others when considering adopting a technology, some researchers did not find social influence to have an impact on individuals' decisions to use health IT (Bozan et al., 2015; Bozan et al., 2016). Tavares and Oliveira (2016) found that social influence did not impact the intention of individuals to adopt patient portals. Hoogenbosch et al. (2018) also reported that social influence did not affect intentions to use patient portals.

Individuals generally want to comply with experts' advice, including advice from their health professionals (Akareem et al., forthcoming; Emani et al., 2016). Health professionals are important referent others to encourage the use of patient portals. For example, Akareem et al. (forthcoming) and Emani et al. (2016) found that physicians can influence the use of patient portals. Hsu et al. (2013) found that individuals were affected by referent others when considering adopting health information systems; their social influence, however, did not include health professionals. Individuals encouraged by their physicians to use a patient portal were twice as likely to use it (Patel \& Johnson, 2018). Emani et al. (2016) found that the strongest influencers to encourage patients to adopt patient portals are physicians and nurses. Crotty et al. (2019) found similar results; physicians influenced patients' adoption of portals. Although the above studies enrich our understanding of the role of health professionals' encouragement on the adoption of patient portals, less is known about its influence on post-adoption use.

\section{Theoretical Framework and Hypothesis Development}

\subsection{Cognitive Dissonance Theory (CDT)}

Festinger (1957) introduced CDT by identifying the discomfort or cognitive dissonance that individuals experience when two or more elements of knowledge are inconsistent or in conflict with their goals. In other words, cognitive dissonance refers to an uncomfortable feeling induced by simultaneously holding two contradictory cognitions. Cognitions or thoughts may include beliefs, attitudes, and behaviors. Individuals feel disharmony and mental discomfort when facing conflicting attitudes, beliefs, or behaviors (Cooper, 2007). They also feel cognitive dissonance when they do not follow directions or suggestions from important others and subsequently take actions to maintain internal consistency (Figl et al., 2019). CDT suggests that individuals take action to change and eradicate dissonance to achieve cognitive consistency. For example, when people recognize that behaviors such as smoking causes ill health but continue to smoke, they experience cognitive dissonance (Fotuhi et al., 2013; McMaster \& Lee, 1991). Therefore, in order to achieve cognitive consistency, they will make efforts to quit smoking.

\subsection{Social Influence: Health Professional Encouragement and CDT}

Fishbein and colleagues (i.e., Ajzen \& Fishbein, 1972; Fishbein, 1979; Fishbein \& Ajzen, 1977) proposed that people are often swayed toward action or behavior when referent others influence them toward it. Individuals are often encouraged by referent others (e.g., physicians) to adopt and use a system regardless of whether they were referring to a health information system (Bozan et al., 2015; Bozan et al., 2016) or patient portal (Hoogenbosch et al., 2018). Akareem et al. (forthcoming), Detmer et al. (2008), and Emani et al. (2016) found support for physicians' influence on patient portal use.

Drawing on CDT and in the context of healthcare, we believe that an individual will strive to maintain harmony and a consistent mindset in their cognition resulting from social influence (health professional encouragement) and their behavior (patient portal use). Since patient portal use is believed to help patients manage their health, encouragement from health professionals will increase patients' continuous use of the portal to preserve the harmonious state of their cognition due to social influence and their behavior. Furthermore, encouragement from health professionals to use a variety of features in the portal will increase patients' structural depth of usage of the portal in managing their health. Thus, health professional encouragement will help increase the continuous use intention and deep structure usage of patient portals. Hence, we propose the following hypotheses:

H1a: Health professional encouragement increases patient portal continuous use intention.

H1b: Health professional encouragement increases patient portal deep structure usage.

\subsection{Security Concerns and Patient Portal Use}

Similar to the context of online banking (Miyazaki \& Fernandez, 2001) and online shopping (Lian \& Lin, 2008), security concerns have threatened the use of patient portals (Angst \& Agarwal, 2009; Archer \& Cocosila, 2014; Hsu et al., 2013; Irizarry et al., 2015; Kruse et al., 2015b; Otte-Trojel et al., 2016; Sakaguchi-Tang et al., 2017; Wakefield et al., 2020). CDT proposes that people can reduce dissonance by changing their beliefs, attitudes, and behaviors or by justifying them (Festinger, 1962). Based on CDT, dissonance, induced by security concerns, triggers the psychological state associated with discomfort, which influences the motivation of individuals to resolve the aroused dissonance (Festinger, 1962) by deciding not to continue to use patient portals or limiting the 
extent of structural usage of the portals to mimimize security concerns associated with their personal information and medical records. As such, we have the following hypotheses:

H2a: Security concerns reduce patient portal continuous use intention.

H2b: Security concerns reduce patient portal deep structure usage.

\subsection{Moderation Effect of Health Professional Encouragement}

Individuals may experience cognitive dissonance when a referent other's recommendation conflicts with their own decisions, concerns, or desires. For example, individuals often express concerns when considering undergoing genetic testing as it might reveal a gene trait for a disease or negative information about their ancestry. Even though they might have this concern and may perceive a dilemma or conflict associated with genetic testing, individuals would consider undergoing testing if their physician recommends it (Turrietta, 2020). Similarly, many smokers have a hard time giving up smoking even when they are aware of the health issues related to their addiction. However, individuals are more likely to adhere to a smoking cessation plan to help them quit smoking when encouraged by their physicians (Butler et al., 2006; Fagerström, 1984; Pederson et al., 1982).

We believe that individuals with security concerns will experience a conflict when health professionals encourage them to use the patient portal. Evidence shows that the higher the social influence, the smaller the negative relationship between perceived risk and usage intention (Chi et al., 2012). Based on CDT, when such a cognitive dissonance arises where opposing cognitions are generated, patients will reduce dissonance by downplaying their security concern beliefs and justifying the change using information from persons of health authority (i.e., health professionals) that reassure them about the concerns. Hence, we believe that health professional encouragement will reduce the negative effects of security concerns on the continuous use intention and deep structure usage of patient portals. Thus, the following hypotheses are proposed:

H3a: Health professional encouragement weakens the negative effect of security concerns on patient portal continuous use intention.

H3b: Health professional encouragement weakens the negative effect of security concerns on patient portal deep structure usage.

\section{Research Method}

Our research model was empirically tested with data collected using an online survey. Participants were recruited using an announcement link to the research study located in the institution's patient portal.

\subsection{Respondents}

Table 1 summarizes the participant's demographic characteristics.

\subsection{Measures}

To maximize construct validity, we adopted most construct items from prior studies in extant literature. Items for measuring security concerns were adopted from Dinev and Hart (2006). Health professional encouragement items were adapted from Zhou and George (2001). Continuous use intention scales were adapted from extant studies (Davis et al., 1992; Kock et al., 2016; Lowry et al., 2015; Venkatesh et al., 2012). The items for deep structure usage were adapted from Burton-Jones and Straub Jr. (2006). A five-point Likert scale ranging from $1=$ strongly disagree to $5=$ strongly agree was used for all constructs. Age, IT experience, exercise, gender, education level, race, and tenure were included as control variables to exclude variance explained by potential confounding factors. The items for the construct measurement are provided in Appendix 1.

\subsection{Measurement Model Assessment}

We used partial least squares structural equation modeling (PLS-SEM) as our statistical method, as it is preferred for exploratory research and when the normal distribution is not met, which is the case in this study - see Table 2 (Hair et al., 2010; Hair et al., 2011). We used the software WarpPLS 7.0 (Kock, 2015) to assess the structural model and the measurement model. Table 2 presents the measurement model reliability, validity, and common method bias analyses. For the measurement model, we assessed the measurement properties in terms of reliability, convergent validity, and discriminant validity. For reliability, we report composite reliability and Cronbach's alpha coefficients in which all values exceeded the suggested threshold of 0.7 (Chin, 1998), indicating that the scales are internally consistent. Convergent validity was assessed by the item loadings for the three factors (i.e., HPE, SC, and CUI in Table 2), which exceeded the suggested threshold of 0.6 (Gefen \& Straub, 2005), indicating that our measurement instrument has acceptable convergent validity. Table 2 shows that all constructs have adequate reliability and validity. 
Table 1 Demographic characteristics

\begin{tabular}{|c|c|c|c|c|c|}
\hline & Category & $\mathrm{N}$ & {$[\%]$} & Mean & SD \\
\hline Age & & & & 49.39 & 13.19 \\
\hline IT Experience & & & & 23.61 & 8.79 \\
\hline \multirow[t]{2}{*}{ Gender } & Female & 137 & 77.40 & & \\
\hline & Male & 40 & 22.60 & & \\
\hline \multirow[t]{2}{*}{ Residential Area } & Urban & 151 & 85.31 & & \\
\hline & Non-urban & 26 & 14.69 & & \\
\hline \multirow[t]{6}{*}{ Race } & American Indian or Alaska Native & 1 & 0.56 & & \\
\hline & Asian & 4 & 2.26 & & \\
\hline & Black or African American & 11 & 6.21 & & \\
\hline & Hispanic or Latino & 4 & 2.26 & & \\
\hline & Native Hawaiian or Other Pacific Islander & 0 & 0 & & \\
\hline & White & 157 & 88.70 & & \\
\hline \multirow[t]{5}{*}{ Education } & High School & 22 & 12.43 & & \\
\hline & Associate Degree & 31 & 17.51 & & \\
\hline & Bachelor Degree & 57 & 32.20 & & \\
\hline & Masters Degree & 43 & 24.29 & & \\
\hline & Doctoral Degree or J.D. & 21 & 11.86 & & \\
\hline
\end{tabular}

Discriminant validity was assessed by observing whether the square root of the average variance extracted (AVE) (shaded diagonal values in Table 3) (Fornell \& Larcker, 1981) is larger than the inter-construct correlations (off-diagonal elements) in the model. Table 3 shows that this criterion is met, indicating that our measurement instrument has acceptable discriminant validity.

Formative measures are indicators that cause a construct (Bollen, 1984). Therefore, unlike reflective constructs, formative constructs do not go through the reliability and validity assessments (Chin, 1998). Instead, formative constructs can be assessed by examining their indicator weights. As such, we assessed the formative deep structure usage construct using the $p$ values of the weights of their indicators and the indicator variance inflation factors (VIFs) to rule out redundancy
(Kock, 2014; Kock \& Mayfield, 2015). All indicators' weights are significant. Potential redundancy in the indicators of the deep structure usage construct is not a concern given that the highest VIF is 2.77, which is lower than the recommended threshold of 5 (Hair et al., 2010). Hence, the patient portal deep structure usage construct was adequately measured in a formative way.

We examined multivariate normality based on Bera and Jarque (1981) and Gel and Gastwirth (2008), as shown in Table 2, indicating that none of our model's constructs met the normal distribution criteria, thus further justifying the use of PLS-based SEM.

Having collected our study data through a survey method (i.e., only one method), common method bias was evaluated by using an approach advised by Kock (2015), which is
Table 2 Construct reliability and validity

\begin{tabular}{lllllllll}
\hline Constructs & Item & HPE & SC & CUI & CR & CA & FVIF & Normal \\
\hline Health Professional & HPE1 & $(0.928)$ & -0.026 & -0.079 & 0.956 & 0.931 & 1.434 & No \\
Encouragement & HPE2 & $(0.955)$ & 0.033 & -0.042 & & & & \\
& HPE3 & $(0.927)$ & -0.029 & 0.013 & & & & \\
Security Concerns & SCl & 0.082 & $(0.818)$ & -0.014 & 0.901 & 0.835 & 1.207 & No \\
& SC2 & -0.015 & $(0.877)$ & 0.043 & & & & \\
Continuous Use Intention & SC3 & -0.089 & $(0.905)$ & 0.084 & & & & \\
& CUI1 & 0.035 & -0.133 & $(0.771)$ & 0.872 & 0.782 & 1.656 & No \\
& CUI2 & -0.085 & 0.173 & $(0.813)$ & & & & \\
\hline
\end{tabular}

Note: All loadmgs significant at $p<0.001 ; \mathrm{CR}=$ composite reliability; $\mathrm{CA}=$ Cronbach's alpha; FVIF = full collinearity variance information factor; Normal $=$ normal distribution (robust Jarque-Bera). HPE $=$ health professional encouragement; $\mathrm{SC}=$ security concerns; $\mathrm{CUI}=$ conti nuous use intention 
Table 3 Inter-construct correlation matrix

\begin{tabular}{llll}
\hline & HPE & SC & CUI \\
\hline HPE & $(0.937)$ & & \\
SC & -0.103 & $(0.867)$ & \\
CUI & 0.492 & -0.382 & $(0.834)$
\end{tabular}

Note: Square roots of average variances extracted (AVE) shown on the diagonal within parentheses; HPE $=$ health professional encouragement; $\mathrm{SC}=$ security concerns; $\mathrm{CUI}=$ continuous use intention

contingent on model-wide collinearity evaluation (Kock \& Lynn, 2012). As recommended, all variance inflation factors (FVIF recorded in Table 2) were lower than the threshold of 5 (Hair et al., 2010). Thus, common method bias is not a threat in this study.

\section{Results}

The results for H1a, H2a and H3a are presented in Fig. 1, where $40 \%$ of the variance in patient portal continuous use intention is explained by the model. Because of the use of a cross-sectional survey, the dependent variable in H1a, H2a, and $\mathrm{H} 3 \mathrm{a}$ is continuous use intention rather than actual continuous use of the portal, and hence, intention is used as a proxy of continuous use (Ajzen, 2020). The dependent variable in $\mathrm{H} 1 \mathrm{~b}, \mathrm{H} 2 \mathrm{~b}$, and $\mathrm{H} 3 \mathrm{~b}$ is deep structure actual usage, which was measured in terms of the diversity of features that were used in the portal. The results for $\mathrm{H} 1 \mathrm{~b}, \mathrm{H} 2 \mathrm{~b}$, and $\mathrm{H} 3 \mathrm{~b}$ are presented in Fig. 2, where $32 \%$ of the variance in patient portal deep structure usage is explained by the model.
All of the hypotheses were supported. Health professional encouragement has a significant effect on patient portal continuous use intention (H1a) $(\beta=.49, p<.001)$. Security concerns also have a significant effect on patient portal continuous use intention $(\mathrm{H} 2 \mathrm{a})(\beta=-.34$, $p<.001)$. As hypothesized, health professional encouragement significantly weakens the negative relationship between security concerns and patient portal continuous use intention (H3a) $(\beta=.14, p=0.030<.05)$, as presented in Fig. 3. Similarly, health professional encouragement has a significant effect on patient portal deep structure actual usage (H1b) $(\beta=.41, p<.001)$. Security concerns have a significant effect on patient portal deep structure usage $(\mathrm{H} 2 \mathrm{~b})(\beta=-.36, \mathrm{p}<.001)$. Health professional encouragement also significantly decreases the negative relationship between security concerns and patient portal deep structure actual usage (H3b) $(\beta=.15, p=0.023$ $<.05)$. None of the control variables in both models has a significant effect on the dependent variables, except for gender in the continuous use intention model, in which females were less likely to continue to use patient portals (Fig. 1: $\beta=-.13, p=0.035<.05$ ) and age in the deep structure actual use mode, in which older patients use it more Fig. 2 : $\beta=.13, p=.038<.05$ ). We believe the gender difference arises because men may have more positve attitudes and higher self-efficacy toward technology, which result in more frequent use of technology (Kay, 2008). We believe that older patients are more likely to use patient portal features due to higher comorobidities. Evidence in the literature suggests that higher number of comorbidities is associated with patient portal adoption (Elston Lafata et al., 2018). Table 4 summarizes the results of hypothesis testing.
Fig. 1 Model 1: H1a, H2a, and $\mathrm{H} 3 \mathrm{a}$ with related coefficients. Note: $* P<0.05 ; * * * P<0.001$

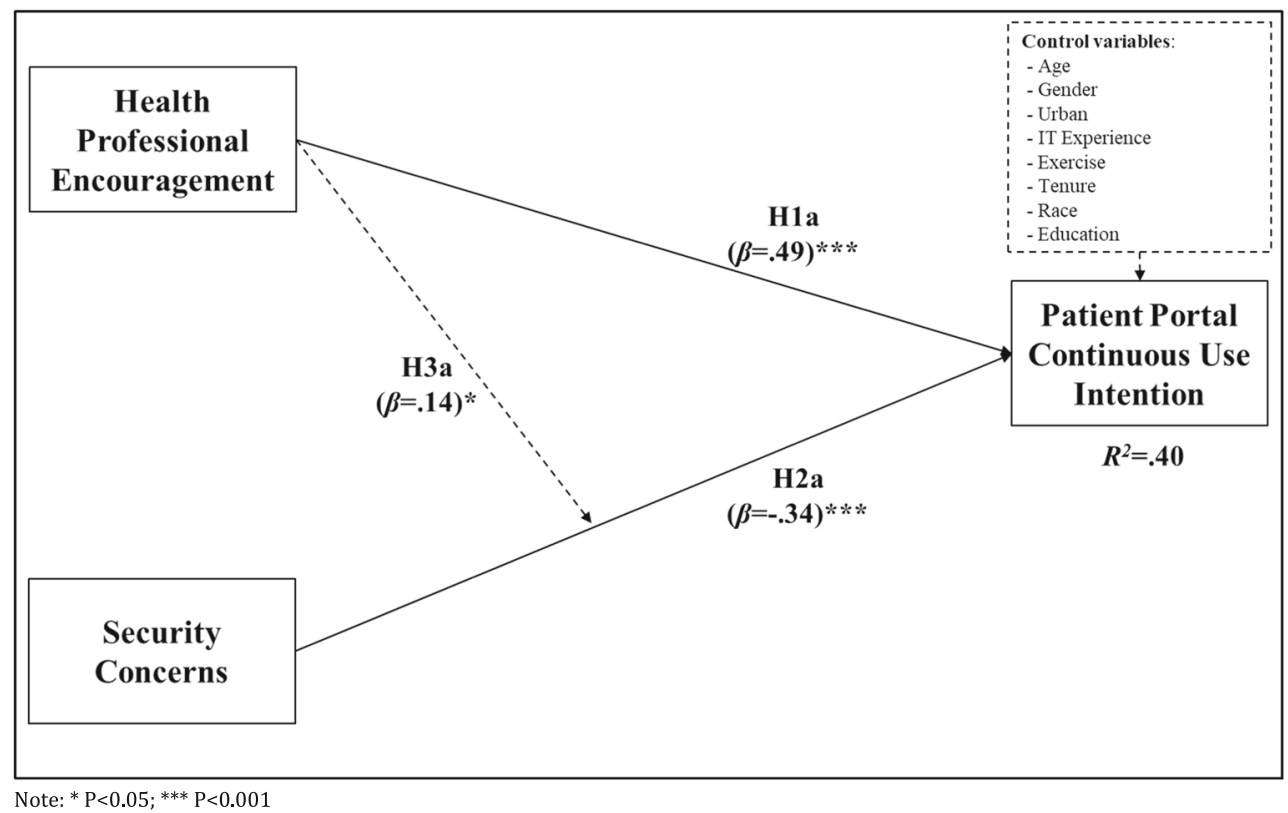


Fig. 2 Model 2: $\mathrm{H} 1 \mathrm{~b}, \mathrm{H} 2 \mathrm{~b}$, and $\mathrm{H} 3 \mathrm{~b}$ with related coefficients. Note: $* \mathrm{P}<0.05 ; * * * \mathrm{P}<0.001$

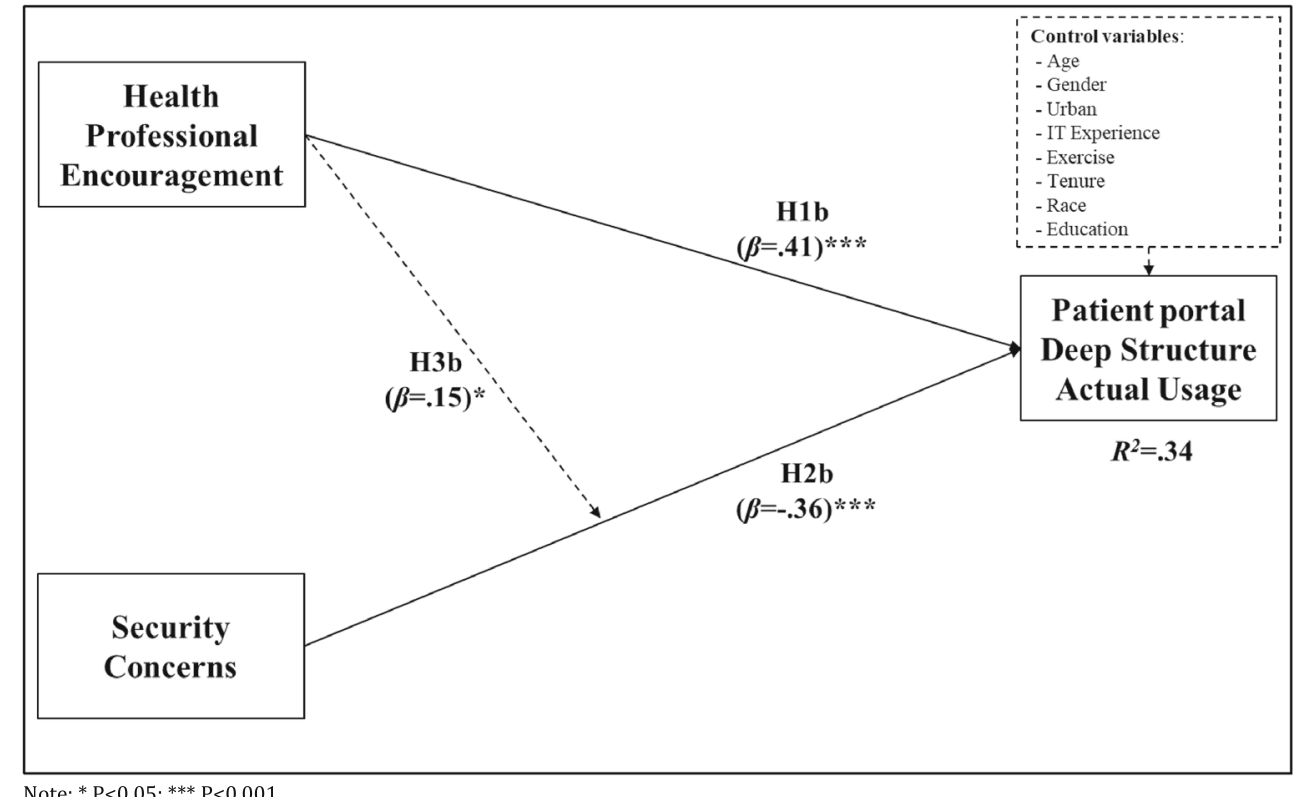

Note: $* \mathrm{P}<0.05 \cdot * * * \mathrm{P}<0.001$

\section{Discussion of Findings}

This research examined cognitive dissonance that gave rise to a moderating effect between factors that encouraged and dissuaded individuals from continuing to use a patient portal and pursuing a deep structure usage through a variety of features in the portal. Specifically, we examined how consonance created by social influence through health professional encouragement increased an individual's decision to not only continue to use a patient portal but also more fully utilize the different features in the portal. We also examined how dissonance created by security concerns negatively impacted an individual's decision to pursue deeper structural usage and continuous use of the patient portal while this negative relationship is further moderated by health professional encouragement.

Hypotheses $1 \mathrm{a}$ and $1 \mathrm{~b}$ examined the positive effect of social influence, represented by health professional encouragement, on individuals' decisions to continue to use and to pursue deep structural usage of a patient portal. This finding is consistent with the literature (Ancker et al., 2011; Angst \& Agarwal, 2009; Irizarry et al., 2015; Wakefield et al., 2012), which indicates that health professionals positively influence adoption decisions to use a patient portal. Thus, steps should be made to ensure that physicians and other health professionals encourage their patients to use patient portals in order to sustain continuous use and achieve deep structure usage of patient portals. Hence, the result suggests that health professional encouragement needs to extend beyond initial adoption to post-adoption use.

Hypotheses $2 \mathrm{a}$ and $2 \mathrm{~b}$ focused on the effect of security concerns on patient portals' continuous use decisions and deep structure usage. Individuals who avoid adopting and using patient portals often cite security concerns as a hindrance to their decision to use the portal. In other words, individuals feel dissonance about using patient portals due to the fear that their medical record might be exposed by a security breach or other unwanted access, as indicated by the strong negative effect we found for security concerns on patient portal continuous use and deep structure usage. These findings are similar to results regarding technology preadoption (Bajracharya et al., 2019; Bodenheimer \& Grumbach, 2003; Cantor, 2001; Collins et al., 2017; Kruse
Table 4 Summary of results of hypothesis testing

\begin{tabular}{lll}
\hline Hypothesis & Hypothesized Relationship & Support? \\
\hline H1a & Health professional encouragement increases continuous use intention & Yes \\
H2a & Security concerns reduce continuous use intention & Yes \\
H3a & Health professional encouragement weakens the negative effect of security concerns & Yes \\
& $\quad$ on continuous use intention & Yes \\
H1b & Health professional encouragement increases deep structure usage & Yes \\
H2b & Security concerns reduce deep structure usage & Yes \\
H3b & Health professional encouragement weakens the negative effect of security concerns & \\
& on deep structure usage &
\end{tabular}


Fig. 3 Health professional encouragement moderation for continuous use intention as the dependent variable

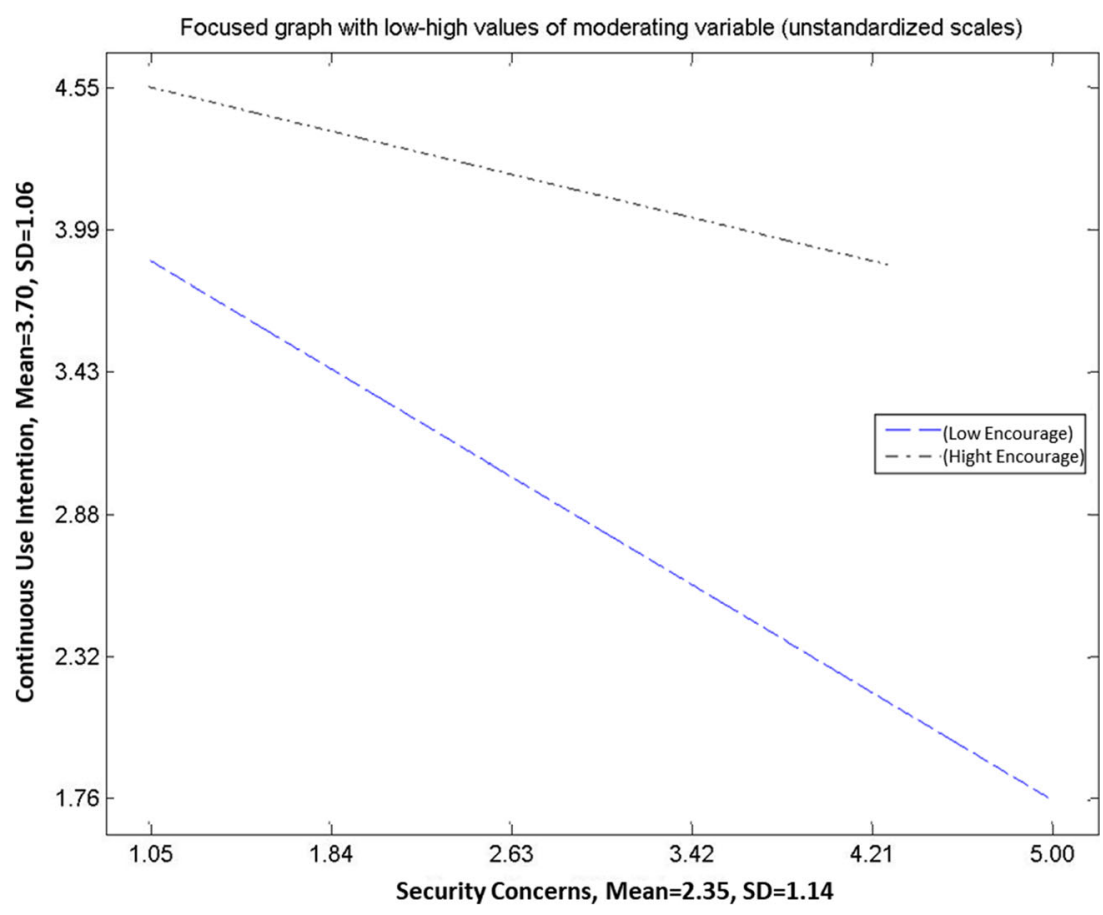

et al., 2015a; Sakaguchi-Tang et al., 2017; Son, 2020). Thus, to increase the deep structure and sustained use of patient portals, mechanisms must be conveyed that alleviate those fears.

Hypotheses $3 \mathrm{a}$ and $3 \mathrm{~b}$ tested the moderating effect of health professional encouragement on the relationship between security concerns and patient portal deep structure usage and continuous use decisions. Based on CDT, it is possible for one or more factors to counteract an individual's concerns or discomfort about completing a task or making a decision. Social influence is a factor that increases patients' willingness to continue to use the patient portal even when they are concerned about system security. In other words, when patients are experiencing cognitive dissonance in the continuous use and deep structure usage of a patient portal, physicians and other health professionals are often most influential to their decision making (Akareem et al., forthcoming; Emani et al., 2016; Otte-Trojel et al., 2016; Patel et al., 2015). In this study, we found support that health professional encouragement reduces and mitigates the negative influence of security concerns on the continuous use and deep structure usage of the patient portal.

In summary, the theoretical models explain a significant percentage of the variance in continuous use of the patient portal $(40 \%)$ and deep structure usage of the patient portal (34\%). The findings indicate that CDT can be used to create a better understanding of the post-adoption use of patient portals. Using CDT to explore how security concerns impact the continuous use of patient portals is important during the COVID-19 pandemic, with many physician offices shuttering their doors and requesting that their patients use the portal for access to their medical records (Heath, 2020). Based on health professionals' encouragement, patients are also increasing their deep structure usage of patient portals in light of COVID-19 to submit the medical power of attorneys and advanced directives (Portz et al., 2020).

\subsection{Theoretical Implications}

First, prior research in health IT has examined antecedents that explain the adoption of patient portals, but, to the best knowledge of the authors, this is the first study that has drawn on CDT to examine cognitive dissonance faced by patients in deciding whether to continue using patient portalsand to pursue deeper structural usage. Hence, this research presents empirical support and a theoretical explanation for the effect of enabling and hindering factors on patient portal post-adoption use. Second, this research contributes to theory by investigating the moderation role of social influence in the form of health professional encouragement on the relationship between security concerns and patient portal continuous use and deep structure usage. The finding suggests that, through the lens of CDT, social influence helps reduce the negative impact of security concerns on post-adoption use.

While some researchers have used CDT in prior research on technology pre-adoption, our findings show that it helps us understand the relative significance and role of two key enabling and hindering factors, particularly in studies that explore the post-adoption continuous use and deep structure usage. For instance, even though patient portal usage is not mandatory, its role has increased in importance during the COVID-19 pandemic, when many physicians are requesting 
that their patients use the portal to access their medical records and manage the communication with health professionals instead of physically visiting the healthcare facility.

\subsection{Managerial Implications}

The findings of this research present important implications for practitioners. The results provide evidence that health professionals' encouragement can lessen the adverse impact of security concerns when a patient is considering whether to continue using a patient portal and engage in deeper structural usage of the portal, similar to those concerns expressed by individuals regarding online banking and online shopping (Lian \& Lin, 2008; Miyazaki \& Fernandez, 2001). Whether the social influence is encouragement from a physician or a healthcare staff member, prior research provides support that individuals receiving such encouragement are more likely to adopt the portal (Crotty et al., 2019; Emani et al., 2016; Hsu et al., 2013; Otte-Trojel et al., 2016; Patel \& Johnson, 2018). Emani et al. (2016) found that the strongest influencers that encourage patients to adopt patient portals were physicians and nurses, while our study demonstrates that health professionals, which include physicians and nurses, have persuasive power over patients' post-adoption use of the portal in terms of continuous use and deep structure usage.

By having health professionals encourage individuals to use patient portals, organizations can lessen the negative impact of hindering factors that created dissonance. For example, patients could be shown short videos by health professionals while they are waiting for their turn to enter the exam room or while being attended to in the treatment room. Their physicians could also speak to them about the importance of using the patient portal in managing their health information. It could be helpful for health professionals to provide information assurance about the system's security instead of just endorsing the system, i.e., similar to trust building in the online banking industry (Merhi et al., 2019; Yu et al., 2015). Physician offices and healthcare facilities could also offer kiosks with added security measures for patients when creating patient portal accounts. The clinics could provide information about the benefits of using a patient portal, the different features available, and ways to protect one's private information when accessing the portal.

An ideal futuristic vision for healthcare providers, system vendors, and policy-makers is the ability to detect and treat diseases before they ravage the body or bankrupt families. There are a few breakthroughs that need to occur before this can happen, and we believe our research is an important step in that direction. This vision can become a reality through better utilization of patient data as well as better healthcare services arising from continuous use and deeper structural usage of patient portals. Continuous use of patient portals can be achieved by (1) having the patient portal developers produce or develop software that patients want to use (i.e., reducing security concerns) or (2) getting the health community to encourage patients to use patient portals (i.e., health professional encouragement) or (3) some of both. If patients are willing to use their patient portal on a continuous and deeper structural basis, the portal can function like software that reads the diagnostic codes of one's car and manages services associated with the car but applied to the realm of healthcare. The marriage of technology and patients is an important stepping stone to a better healthcare and medical system in the future.

\subsection{Limitations and Future Research}

One limitation is that the study included patients from only one healthcare facility, and thus, the degree of generalizability of the findings may be limited. Future research and replications of the study are needed to assess the generalizability of the findings. Although the two key factors in this study explain a large proportion of the variance in patient portal continuous use and deep structure usage (i.e., $40 \%$ and $34 \%$ respectively), future research could explore other factors that may influence the post-adoption use of patient portals such as social influence from other referents and concerns for one's health and privacy. Additionally, although the respondents in this study may indicate their willingness to continue using the patient portal, future research needs to assess if such intentions translate into actual continuous use.

\section{Conclusion}

In this study, health professional encouragement and security concerns are identified as antecedents of continuous use and deep structure usage of patient portals by users through the lens of CDT. The findings indicate that social influence through health professional encouragement augments postadoption use of patient portals. The results also indicate that security concerns impede an individual's decision to continue using a patient portal and engage in deeper structural usage. Interestingly, the positive influence of encouragement to use the patient portal by health professionals explains more variance in post-adoption use (i.e., continuous use and deep structure usage) than security concerns. The negative impact of security concerns on post-adoption use is moderated or reduced when patients receive health professional encouragement. Therefore, health professional encouragement not only has a positive effect on patients' continuous use and deep structure usage of the portal but also helps mitigate the threat of security concerns on post-adoption use. Thus, the findings of this research are substantial for enhancing our understanding of the relationship between cognitive dissonance and postadoption use of patient portals. 


\section{Appendix 1 Measurement instrument}

\begin{tabular}{|c|c|c|}
\hline Construct & Items & Source \\
\hline $\begin{array}{l}\text { Health Professional } \\
\text { Encouragement }\end{array}$ & $\begin{array}{l}\text { Usage of MyChart is encouraged by my healthcare professional team (e.g., healthcare } \\
\text { provider/doctor, office staff, practice administrators). } \\
\text { My healthcare professional team endorses MyChart usage. } \\
\text { My healthcare professional team supports involvement in MyChart usage. }\end{array}$ & Zhou and George (2001) \\
\hline Security Concerns & $\begin{array}{l}\text { I am concerned about submitting information on MyChart because of the potential for security } \\
\text { breaches. } \\
\text { I am concerned that information on MyChart could be accessed by unauthorized parties who } \\
\text { hack into the system. } \\
\text { I am concerned about submitting information on MyChart because others might hack into the } \\
\text { system. }\end{array}$ & Dinev and Hart (2006) \\
\hline $\begin{array}{l}\text { Continuous Use } \\
\text { Intention }\end{array}$ & $\begin{array}{l}\text { I intend to continue using MyChart in the future. } \\
\text { I will always try to use MyChart in my daily life. } \\
\text { I plan to continue to use MyChart frequently. }\end{array}$ & $\begin{array}{l}\text { Kock et al. (2016); Lowry } \\
\quad \text { et al. (2015) }\end{array}$ \\
\hline Deep Structure Usage & $\begin{array}{l}\text { When I was using MyChart, I used features that helped me to see my lab results. } \\
\text { When I was using MyChart, I used features that helped me to request a refill. } \\
\text { When I was using MyChart, I used features that helped me to send a message to my provider. } \\
\text { When I was using my MyChart, I used features that helped me to track my health progress over } \\
\text { time. } \\
\text { When I was using my MyChart, I used features that helped me to learn more about my medical } \\
\text { condition. } \\
\text { When I was using my MyChart, I used features that helped me to manage my healthcare. }\end{array}$ & $\begin{array}{l}\text { Burton-Jones and Straub } \\
\text { Jr. (2006) }\end{array}$ \\
\hline
\end{tabular}

\section{References}

Abd-alrazaq, A. A., Bewick, B. M., Farragher, T., and Gardner, P. (2019). "factors that affect the use of electronic personal health records among patients: A systematic review," International Journal of Medical Informatics (126), pp. 164-175.

Ajzen, I. (1991). The theory of planned behavior. Organizational Behavior and Human Decision Processes, 50, 179-211.

Ajzen, I. (2020). The theory of planned behavior: Frequently asked questions. Human Behavior and Emerging Technologies, 2(4), 314-324.

Ajzen, I., \& Fishbein, M. (1972). Attitudes and normative beliefs as factors influencing behavioral intentions. Journal of Personality and Social Psychology, 21(1), 1-9.

Akareem, H. S., Ferdous, A. S., and Todd, M. (forthcoming). "Impact of patient portal behavioral engagement on subsistence consumers' wellbeing," International Journal of Research in Marketing).

Alhudaithy, A. I., \& Kitchen, P. J. (2009). Rethinking models of technology adoption for internet banking: The role of website features. Journal of Financial Services Marketing, 14(1), 56-69.

Ancker, J. S., Barrón, Y., Rockoff, M. L., Hauser, D., Pichardo, M., Szerencsy, A., \& Calman, N. (2011). Use of an electronic patient portal among disadvantaged populations. Journal of General Internal Medicine, 26(10), 1117-1123.

Angst, C. M., \& Agarwal, R. (2009). Adoption of electronic health records in the presence of privacy concerns: The elaboration likelihood model and individual persuasion. MIS Quarterly, 33(2), 339-370.

Anthony, D. L., Campos-Castillo, C., \& Lim, P. S. (2018). Who isn't using patient portals and why? Evidence and implications from a national sample of US adults. Health Affairs, 37(12), 1948-1954.

Archer, N., \& Cocosila, M. (2014). Canadian patient perceptions of electronic personal health records: An empirical investigation.
Communications of the Association for Information Systems, 34(20), 390-406.

Bajracharya, A. S., Crotty, B. H., Kowoloff, H. B., Safran, C., \& Slack, W. V. (2019). Patient experience with family history tool: Analysis of patients' experience sharing their family health history through patient-computer dialogue in a patient portal. Journal of the American Medical Informatics Association, 26(7), 603-609.

Bera, A. K., \& Jarque, C. M. (1981). Efficient tests for normality, homoscedasticity and serial independence of regression residuals: Monte Carlo evidence. Economics Letters, 7(4), 313-318.

Bodenheimer, T., \& Grumbach, K. (2003). Electronic technology: A spark to revitalize primary care? JAMA, 290(2), 259-264.

Bollen, K. A. (1984). Multiple indicators: Internal consistency or no necessary relationship? Quality and Quantity, 18(4), 377-385.

Bozan, K., Davey, B., \& Parker, K. (2015). Social influence on health IT adoption patterns of the elderly: An institutional theory based use behavior approach. Procedia Computer Science, 63, 517-523.

Bozan, K., Parker, K., and Davey, B. (2016). "a closer look at the social influence construct in the UTAUT model: An institutional theory based approach to investigate health IT adoption patterns of the elderly," 2016 49th Hawaii International Conference on System Sciences (HICSS): IEEE, pp. 3105-3114.

Burton-Jones, A., \& Straub Jr., D. W. (2006). Reconceptualizing system usage: An approach and empirical test. Information Systems Research, 17(3), 228-246.

Butler, J., Speroff, T., Arbogast, P. G., Newton, M., Waitman, L. R., Stiles, R., Miller, R. A., Ray, W., \& Griffin, M. R. (2006). Improved compliance with quality measures at hospital discharge with a computerized physician order entry system. American Heart Journal, 151(3), 643-653.

Byczkowski, T. L., Munafo, J. K., \& Britto, M. T. (2014). Family perceptions of the usability and value of chronic disease web-based patient portals. Health Informatics Journal, 20(2), 151-162. 
Cantor, J. D. (2001). Privacy protections for cybercharts: An update on the law. JAMA, 285(13), 1767-1767.

Chi, H., Yeh, H., \& Hung, W.-C. (2012). The moderating effect of subjective norm on cloud computing users' perceived risk and usage intention. International Journal of Marketing Studies, 4(6), 95-102.

Chin, W. (1998). The partial least squares approach to structural equation modeling. Modern Methods for Business Research, 295(2), 295-336.

Collins, S. A., Rozenblum, R., Leung, W. Y., Morrison, C. R., Stade, D. L., McNally, K., Bourie, P. Q., Massaro, A., Bokser, S., \& Dwyer, C. (2017). Acute care patient portals: A qualitative study of stakeholder perspectives on current practices. Journal of the American Medical Informatics Association, 24(e1), e9-e17.

Cooper, J. (2007). Cognitive dissonance: 50 years of a classic theory. Sage.

Crotty, B. H., Winn, A. N., Asan, O., Nagavally, S., Walker, R. J., \& Egede, L. E. (2019). Clinician encouragement and online health record usage. Journal of General Internal Medicine, 34(11), 2345-2347.

Dai, H., and Chen, Y. (2015). "effects of exchange benefits, security concerns and situational privacy concerns on mobile commerce adoption," journal of International Technology and Information Management (24:3), pp. 41-56.

Davis, F., Bagozzi, R., \& Warshaw, P. (1992). Extrinsic and intrinsic motivation to use computers in the workplace1. Journal of Applied Social Psychology, 22(14), 1111-1132.

Detmer, D., Bloomrosen, M., Raymond, B., \& Tang, P. (2008). Integrated personal health records: Transformative tools for consumer-centric care. BMC Medical Informatics and Decision Making, 8(1), 1-14.

Dinev, T., \& Hart, P. (2006). An extended privacy calculus model for ecommerce transactions. Information Systems Research, 17(1), 61-80.

Elston Lafata, J., Miller, C. A., Shires, D. A., Dyer, K., Ratliff, S. M., \& Schreiber, M. (2018). Patients' adoption of and feature access within electronic patient portals. The American Journal of Managed Care, 24(11), e352-e357.

Emani, S., Healey, M., Ting, D. Y., Lipsitz, S. R., Ramelson, H., Suric, V., and Bates, D. W. (2016). "awareness and use of the after-visit summary through a patient portal: Evaluation of patient characteristics and an application of the theory of planned behavior," Journal of Medical Internet Research (18:4), p. e77.

Emani, S., Peters, E., Desai, S., Karson, A. S., Lipsitz, S. R., LaRocca, R., Stone, J., Suric, V., Wald, J. S., \& Wheeler, A. (2018). Perceptions of adopters versus non-adopters of a patient portal: An application of diffusion of innovation theory. BMJ Health \& Care Informatics, 25(3), 149-157.

Fagerström, K.-O. (1984). Effects of nicotine chewing gum and followup appointments in physician-based smoking cessation. Preventive Medicine, 13(5), 517-527.

Featherman, M. S., Miyazaki, A. D., \& Sprott, D. E. (2010). Reducing online privacy risk to facilitate e-service adoption: The influence of perceived ease of use and corporate credibility. Journal of Services Marketing, 24(3), 219-229.

Federal Reserve. (2016). "consumers and mobile financial services 2016, " Board of Governors of the Federal Reserve System).

Festinger, L. (1957). Cognitive dissonance theory. Stanford University Press.

Festinger, L. (1962). Cognitive dissonance. Scientific American, 207(4), 93-106.

Figl, K., Kießling, S., Rank, C., \& Vakulenko, S. (2019). Fake news flags, cognitive dissonance, and the believability of social media posts (pp. 1-9). International Conference on Information Systems.

Fishbein, M. (1979). A theory of reasoned action: Some applications and implications. Nebraska Symposium on Motivatio, 27, 65-116.

Fishbein, M., \& Ajzen, I. (1977). Belief, attitude, intention, and behavior: An introduction to theory and research. Addison-Wesley.

Fornell, C., \& Larcker, D. (1981). Evaluating structural equation models with unobservable variables and measurement error. Journal of Marketing Research, 18(1), 39-50.
Fotuhi, O., Fong, G. T., Zanna, M. P., Borland, R., Yong, H.-H., \& Cummings, K. M. (2013). Patterns of cognitive dissonancereducing beliefs among smokers: A longitudinal analysis from the international tobacco control (ITC) four country survey. Tobacco Control, 22(1), 52-58.

Fowles, J. B., Kind, A. C., Craft, C., Kind, E. A., Mandel, J. L., \& Adlis, S. (2004). Patients' interest in reading their medical record: Relation with clinical and sociodemographic characteristics and patients' approach to health care. Archives of Internal Medicine, 164(7), 793-800.

Fraccaro, P., Vigo, M., Balatsoukas, P., Buchan, I. E., Peek, N., \& van der Veer, S. N. (2018). The influence of patient portals on users' decision making is insufficiently investigated: A systematic methodological review. International Journal of Medical Informatics, 111, $100-111$.

Gefen, D., \& Straub, D. (2005). A practical guide to factorial validity using PLS-graph: Tutorial and annotated example. Communications of the Association for Information Systems, 16(1), 91-109.

Gel, Y. R., \& Gastwirth, J. L. (2008). A robust modification of the Jarque-Bera test of normality. Economics Letters, 99(1), 30-32.

Goel, M. S., Brown, T. L., Williams, A., Cooper, A. J., Hasnain-Wynia, R., and Baker, D. W. (2011a). "patient reported barriers to enrolling in a patient portal," Journal of the American Medical Informatics Association (18:Supplement 1), pp. i8-i12.

Goel, M. S., Brown, T. L., Williams, A., Hasnain-Wynia, R., Thompson, J. A., \& Baker, D. W. (2011b). Disparities in enrollment and use of an electronic patient portal. Journal of General Internal Medicine, 26(10), 1112-1116.

Hair, J., Black, W., Babin, B., and Anderson, R. (2010). Multivariate data analysis. Upper Saddle River, N.J.; London: Pearson.

Hair, J. F., Ringle, C. M., \& Sarstedt, M. (2011). PLS-SEM: Indeed a silver bullet. The Journal of Marketing Theory and Practice, 19(2), 139-152.

Heath, S. (2018a). "patient portal access, use reach $52 \%$ of healthcare consumers." Patient Data Acceess News retrieved 10/29/2019, 2019, from https://patientengagementhit.com/news/patient-portalaccess-use-reach-52-of-healthcare-consumers

Heath, S. (2018b). "patient portal adoption tops $90 \%$, but strong patient use is needed." Patient Data Access News retrieved 10/29/2019, 2019, from https://patientengagementhit.com/news/patient-portaladoption-tops-90-but-strong-patient-use-is-needed

Heath, S. (2020). "Was COVID-19 healthcare's use case for the patient portal?" Patient Data Access News Retrieved 10/24/2020, 2020, from https://patientengagementhit.com/features/was-covid-19healthcares-use-case-for-the-patient-portal

Hoogenbosch, B., Postma, J., Janneke, M., Tiemessen, N. A., van Delden, J. J., and van Os-Medendorp, H. (2018). "use and the users of a patient portal: Cross-sectional study," Journal of Medical Internet Research (20:9), p. e262.

Hsu, C., Lee, M.-R., and Su, C.-H. (2013). "the role of privacy protection in healthcare information systems adoption," Journal of Medical Systems (37:5), p. 9966.

Hsu, J., Huang, J., Kinsman, J., Fireman, B., Miller, R., Selby, J., \& Ortiz, E. (2005). Use of e-health services between 1999 and 2002: A growing digital divide. Journal of the American Medical Informatics Association, 12(2), 164-171.

Huvila, I., Enwald, H., Eriksson-Backa, K., Hirvonen, N., Nguyen, H., \& Scandurra, I. (2018). Anticipating ageing: Older adults reading their medical records. Information Processing \& Management, 54(3), 394- 407.

Ifinedo, P. (2012). Understanding information systems security policy compliance: An integration of the theory of planned behavior and the protection motivation theory. Computers \& Security, 31(1), 83-95.

Irizarry, T., Dabbs, A. D., and Curran, C. R. (2015). "patient portals and patient engagement: A state of the science review," Journal of Medical Internet Research (17:6), p. e148. 
Kay, R. (2008). "exploring gender differences in computer-related behaviour: Past, present, and future," in Social information technology: Connecting society and cultural issues. Hershey, PA: IGI Global, pp. $12-30$.

Kim, J., and Park, H.-A. (2012). "development of a health information technology acceptance model using consumers' health behavior intention," Journal of Medical Internet Research (14:5), p. e133.

Kock, N. (2014). Advanced mediating effects tests, multi-group analyses, and measurement model assessments in PLS-based SEM. International Journal of e-Collaboration (IJeC), 10(1), 1-13.

Kock, N. (2015). Common method bias in PLS-SEM: A full collinearity assessment approach. International Journal of e-Collaboration, 11(4), $1-10$.

Kock, N., \& Lynn, G. (2012). Lateral collinearity and misleading results in variance-based SEM: An illustration and recommendations. Journal of the Association for Information Systems, 13(7), 546-580.

Kock, N., \& Mayfield, M. (2015). PLS-based SEM algorithms: The good neighbor assumption, collinearity, and nonlinearity. Information Management and Business Review, 7(2), 113-130.

Kock, N., Moqbel, M., Barton, K., \& Bartelt, V. (2016). Intended continued use of social networking sites: Effects on job satisfaction and performance. International Journal of Virtual Communities and Social Networking, 8(2), 28-46.

Kruse, C. S., Argueta, D. A., Lopez, L., and Nair, A. (2015a). "patient and provider attitudes toward the use of patient portals for the management of chronic disease: A systematic review," Journal of Medical Internet Research (17:2).

Kruse, C. S., Bolton, K., and Freriks, G. (2015b). "the effect of patient portals on quality outcomes and its implications to meaningful use: A systematic review," Journal of Medical Internet Research (17:2).

Li, H., Gupta, A., Zhang, J., \& Sarathy, R. (2014). Examining the decision to use standalone personal health record systems as a trustenabled fair social contract. Decision Support Systems, 57, 376-386.

Lian, J.-W., \& Lin, T.-M. (2008). Effects of consumer characteristics on their acceptance of online shopping: Comparisons among different product types. Computers in Human Behavior, 24(1), 48-65.

Liu, L., and Zhang, Y. (2014). "Enhancing teachers' professional development through reflective teaching," Theory and Practice in Language Studies (4:11), p. 2396.

Lowry, P., Gaskin, J., \& Moody, G. (2015). Proposing the multi-motive information systems continuance model (MISC) to better explain end-user system evaluations and continuance intentions. Journal of the Association for Information Systems, 16(7), 515-579.

Lunney, A., Cunningham, N. R., \& Eastin, M. S. (2016). Wearable fitness technology: A structural investigation into acceptance and perceived fitness outcomes. Computers in Human Behavior, 65, 114-120.

Marikyan, D., Papagiannidis, S., and Alamanos, E. (2020). "cognitive dissonance in technology adoption: A study of smart home users," Information Systems Frontiers), pp. 1-23.

McMaster, C., \& Lee, C. (1991). Cognitive dissonance in tobacco smokers. Addictive Behaviors, 16(5), 349-353.

Merhi, M., Hone, K., \& Tarhini, A. (2019). A cross-cultural study of the intention to use mobile banking between Lebanese and British consumers: Extending UTAUT2 with security, privacy and trust. Technology in Society, 59, 101151.

Miyazaki, A. D., \& Fernandez, A. (2001). Consumer perceptions of privacy and security risks for online shopping. Journal of Consumer Affairs, 35(1), 27-44.

Moqbel, M. (2012). Understanding workplace adoption of social networking sites: Employers' perspective. Studies in Business and Economics, 16, 37-54.

Moqbel, M., Rahman, M., Cho, Y., \& Hewitt, B. (2020). Sustaining patient engagement: The role of health emotion and personality traits in patient portal continuous use decision. AIS Transactions on Human-Computer Interaction, 12(4), 172-198.
Mukherjee, A., \& Nath, P. (2003). A model of trust in online relationship banking. International Journal of Bank Marketing, 21(1), 5-15.

Nah, F. F.-H., \& Tan, X. (2015). An emergent model of end-users' acceptance of enterprise resource planning systems: A grounded theory approach. Journal of Database Management, 26(4), 44-66.

Nicholas, D., Huntington, P., \& Williams, P. (2003). Three years of digital consumer health information: A longitudinal study of the touch screen health kiosk. Information Processing \& Management, 39(3), 479-502.

O'Connor, Y., \& O'Reilly, P. (2018). Examining the infusion of mobile technology by healthcare practitioners in a hospital setting. Information Systems Frontiers, 20(6), 1297-1317.

Otte-Trojel, T., Bont, A. d., Aspria, M., Adams, S., Rundall, T. G., \& Klundert, J. v. d., and Mul, M. d. (2015). Developing patient portals in a fragmented healthcare system. International Journal of Medical Informatics, 84(10), 835-846.

Otte-Trojel, T., de Bont, A., Rundall, T. G., \& van de Klundert, J. (2016). What do we know about developing patient portals? A systematic literature review. Journal of the American Medical Informatics Association, 23(e1), e162-e168.

Patel, V., Barker, W., and Siminerio, E. (2015). "trends in consumer access and use of electronic health information," U.S. Department of Health and Human Services, HealthIT.gov dashboard.

Patel, V., \& Johnson, C. (2018). Individuals' use of online medical records and technology for health needs. The Office of the National Coordinator.

Pederson, L. L., Baskerville, J. C., \& Wanklin, J. M. (1982). Multivariate statistical models for predicting change in smoking behavior following physician advice to quit smoking. Preventive Medicine, 11(5), 536-549.

Portz, J. D., Brungardt, A., Shanbhag, P., Staton, E. W., Bose-Brill, S., Lin, C.-T., Kutner, J. S., and Lum, H. D. (2020). "advance care planning among users of a patient portal during the COVID-19 pandemic: Retrospective observational study," Journal of Medical Internet Research (22:8), p. e21385.

Raghu, T. S., Frey, K., Chang, Y.-H., Cheng, M.-R., Freimund, S., \& Patel, A. (2015). Using secure messaging to update medications list in ambulatory care setting. International Journal of Medical Informatics, 84(10), 754-762.

Rathert, C., Porter, T. H., Mittler, J. N., \& Fleig-Palmer, M. (2019). Seven years after meaningful use: Physicians' and nurses' experiences with electronic health records. Health Care Management Review, 44(1), 30-40.

Razmak, J., \& Bélanger, C. (2018). Using the technology acceptance model to predict patient attitude toward personal health records in regional communities. Information Technology \& People, 31, 306-326.

Roblin, D. W., Houston, T. K., Allison, J. J., Joski, P. J., \& Becker, E. R. (2009). Disparities in use of a personal health record in a managed care organization. Journal of the American Medical Informatics Association, 16(5), 683-689.

Sakaguchi-Tang, D. K., Bosold, A. L., Choi, Y. K., and Turner, A. M. (2017). "patient portal use and experience among older adults: Systematic review," JMIR Medical Informatics (5:4), p. e38.

Sarkar, U., Karter, A. J., Liu, J. Y., Adler, N. E., Nguyen, R., López, A., \& Schillinger, D. (2010). The literacy divide: Health literacy and the use of an internet-based patient portal in an integrated health system-Results from the diabetes study of northern California (DISTANCE). Journal of Health Communication, 15(S2), 183-196.

Sarkar, U., Karter, A. J., Liu, J. Y., Adler, N. E., Nguyen, R., López, A., \& Schillinger, D. (2011). Social disparities in internet patient portal use in diabetes: Evidence that the digital divide extends beyond access. Journal of the American Medical Informatics Association, 18(3), 318-321.

Sathye, M. (1999). Adoption of internet banking by Australian consumers: An empirical investigation. International Journal of Bank Marketing, 17(7), 324-334.

Schickedanz, A., Huang, D., Lopez, A., Cheung, E., Lyles, C., Bodenheimer, T., \& Sarkar, U. (2013). Access, interest, and 
attitudes toward electronic communication for health care among patients in the medical safety net. Journal of General Internal Medicine, 28(7), 914-920.

Seethamraju, R., Diatha, K. S., \& Garg, S. (2018). Intention to use a mobile-based information technology solution for tuberculosis treatment monitoring-applying a UTAUT model. Information Systems Frontiers, 20(1), 163-181.

Serrano, A., Garcia-Guzman, J., Xydopoulos, G., \& Tarhini, A. (2020). Analysis of barriers to the deployment of health information systems: A stakeholder perspective. Information Systems Frontiers, 22(2), 455-474.

Son, H. (2020). "Adult patients' experience using patient portal: The impact of perceived usability on portal use behavior." University of Maryland Baltimore.

Son, H., Nahm, E. S., Zhu, S., Galik, E., Seidl, K. L., Van de Castle, B., \& Russomanno, V. (2021). Testing a model of patient portal use in adult patients. Journal of Nursing Scholarship, 53(2), 143-153.

Tavares, J., and Oliveira, T. (2016). "electronic health record patient portal adoption by health care consumers: An acceptance model and survey," Journal of Medical Internet Research (18:3), p. e49.

Terry, N. (2014). Health privacy is difficult but not impossible in a postHIPAA data-driven world. Chest, 146(3), 835-840.

Thambusamy, R., \& Palvia, P. (2020). US healthcare provider capabilities and performance: The mediating roles of service innovation and quality. Information Systems Frontiers, 22(1), 91-111.

Turrietta, C. M. (2020). Using the health belief model to predict an individual's willingness to conduct genetic testing. Texas State University.

Venkatesh, V., and Goyal, S. (2010). "expectation disconfirmation and technology adoption: Polynomial modeling and response surface analysis," MIS Quarterly), pp. 281-303.

Venkatesh, V., Thong, J., \& Xu, X. (2012). Consumer acceptance and use of information technology: Extending the unified theory of acceptance and use of technology. MIS Quarterly, 36(1), 157-178.

Wade-Vuturo, A. E., Mayberry, L. S., \& Osborn, C. Y. (2013). Secure messaging and diabetes management: Experiences and perspectives of patient portal users. Journal of the American Medical Informatics Association, 20(3), 519-525.

Wakefield, B. J., Turvey, C., Hogan, T., Shimada, S., Nazi, K., Cao, L., Stroupe, K., Martinez, R., and Smith, B. (2020). "impact of patient portal use on duplicate laboratory tests in diabetes management," Telemedicine and e-Health (26:10).

Wakefield, D. S., Kruse, R. L., Wakefield, B. J., Koopman, R. J., Keplinger, L. E., Canfield, S. M., \& Mehr, D. R. (2012). Consistency of patient preferences about a secure internet-based patient communications portal: Contemplating, enrolling, and using. American Journal of Medical Quality, 27(6), 494-502.

Wang, X., Sun, J., Wang, Y., and Liu, Y. (2021). "deepen electronic health record diffusion beyond breadth: Game changers and decision drivers," Information Systems Frontiers), pp. 1-12.

Weingart, S. N., Rind, D., Tofias, Z., \& Sands, D. Z. (2006). Who uses the patient internet portal? The PatientSite experience. Journal of the American Medical Informatics Association, 13(1), 91-95.

Yu, P. L., Balaji, M., \& Khong, K. W. (2015). Building trust in internet banking: A trustworthiness perspective. Industrial Management \& Data Systems, 115(2), 235-252.

Zailani, S., Iranmanesh, M., Nikbin, D., and Beng, J. K. C. (2015). "determinants of RFID adoption in Malaysia's healthcare industry: Occupational level as a moderator," Journal of Medical Systems (39:1), p. 172.

Zhou, J., \& George, J. M. (2001). When job dissatisfaction leads to creativity: Encouraging the expression of voice. The Academy of Management Journal, 44(4), 682-696.
Publisher's Note Springer Nature remains neutral with regard to jurisdictional claims in published maps and institutional affiliations.

Murad Moqbel is Assistant Professor of Information Systems and the founding director of Master of Science in Business Analytics at the University of Texas Rio Grande Valley. He holds a Ph.D. degree in Management Information Systems from Texas A\&M International University. He graduated Cum Laude with a bachelor's in business administration and computer information systems, and he received an MBA with information systems concentration, from Emporia State University, Emporia, Kansas. He has authored and co-authored several papers that appeared in: Information \& Management, Information Technology and People, Journal of Computer Information Systems, AIS Transactions on $\mathrm{HCI}$, Internet Research, the proceedings of major IS conferences including ICIS, HICSS, and AMCIS. His research interests focus on the interaction between human behavior and information technologies including social media, emerging technologies and Health IT, information security and privacy, and international business.

Barbara Hewitt is an Assistant Professor in the Department of Health Information Management at Texas State University. She received her Ph.D. in Information Technology (IT) and her BS in Computer Science from the University of Texas at San Antonio. She also has a Master in Business Administration from Texas State University. Her research interests include securing information systems including electronic health records, knowledge sharing, adoption of and gamification of electronic health records, and healthy people including wearables. She has papers in Communication of the Association of Information Systems, International Journal of Knowledge Management, Journal of Information Privacy and Security. International Journal of Healthcare Technology and Management, Perspectives in Health Information Management, and DATA BASE.

Fiona Fui-Hoon Nah is a Professor of Business \& Information Technology at the Missouri University of Science and Technology. She is Editor-in-chief of the AIS Transactions on Human-Computer Interaction, and a co-Founder and former Chair of SIGHCI. Her research interests include human-computer interaction, virtual communities and virtual worlds, electronic commerce, mobile and ubiquitous commerce, enterprise resource planning, usable security, and neuro-IS. Her publications have appeared in journals such as MIS Quarterly, Journal of the Association for Information Systems, and International Journal of Human-Computer Studies. She received her Ph.D. in Management Information Systems from the University of British Columbia.

Rosann M. McLean is Department Chair and a Clinical Assistant Professor at the University of Kansas School of Health Professions Department of Health Information Management. She is a review panelist for Perspectives in Health Information Management and served as an expert reviewer of a textbook on the topic of electronic health records published by Paradigm Education Solutions. In the healthcare industry prior to entering academia, she managed health information systems and served on information privacy and security committees. She has presented at numerous health information management and health informatics professional association conferences on a variety of topics. She received her Doctor of Health Sciences with concentration in global health from A.T. Still University in Mesa, AZ. 